\title{
Рентгеновская оптика: как и что мы увидим?
}

\begin{abstract}
Область применения рефракционной оптики существенно расширилась, значительно перекрыв зону применения традиционных рентгеновской оптики кристаллов и зеркал. Но для астрофизических задач рентгеновская оптика косого скольжения остается незаменимым инструментом. Сложность задачи заключается в изготовлении многослойных интерференционных зеркал, преломляющих линз, и перестраиваемых преломляющих линз - трансфокаторов. Для использования их потенциала необходима рентгеновская оптика дифракционного качества. А в области рентгеновской микротомографии возможности повышения чувствительности скрыты в использовании рентгено-оптических элементов: капилярных линз, зонных пластинок Френеля, асимметричных отражающих кристаллов (Bragg magnifiers), многослойных рентгеновских зеркал.
\end{abstract}

K аковы перспективы использования рентгеновской оптики? Об этом в своем докладе «Преломляющая рентгеновская оптика: статус, проблемы и перспективы" рассказал А.А.Снигирев (Балтийский федеральный университет имени Имануила Канта, Калининград, Россия). С момента первой успешной экспериментальной демонстрации фокусировки преломляющими линзами рентгеновских лучей [1], область применения рефракционной оптики существенно расширилась, значительно перекрыв зону применения традиционной рентгеновской оптики - кристаллов и зеркал. Сегодня такая оптика активно используется на всех современных высоко-энергетичных (>2 ГэВ) источниках синхротронного излучения 3-го поколения и лазерах на свободных электронах (XFEL). Такое стремительное развитие связано с успехами разработок самих оптических элементов и созданием специальных перестраиваемых устройств на основе преломляющих линз - трансфокаторов [2], позволяющих работать в широком диапазоне энергий от 2 до 200 кэВ. Помимо их применения в традиционных задачах микрофокусировки, они также могут использоваться в качестве конденсоров с настраиваемым размером пучка, коллиматоров, обеспечивающих микро-радианную расходимость пучка, монохроматоров - фильтров низких частот [2], устройств для подавления высоких гармоник [3], Фурье преобразователей [4].

Улучшенные характеристики пучков, производимых новыми источниками синхротронного излучения 4-го поколения с уменьшенным горизонтальным эмиттансом, откроют уникальную возможность для создания эффективных систем транспорта пучка на основе преломляющей оптики. В связи с существенным уменьшением горизонтального размера источника и расходимости пучка такие системы могут передавать пучок фотонов практически без потерь от источника до исследуемого образца или любых промежуточных узлов оптической схемы (зеркал, кристаллов, линз и т.д.). Очевидно, экспериментальные станции получат значительные преимущества при использовании легко перестраиваемых систем на основе преломляющих линз, установленных сразу после источника. В этой связи разработка радиационно- и термоустойчивой алмазной оптики имеет решающее значение [5-8]. Реализация системы транспортировки пучка на основе преломляющих линз значительно упростит компоновку большинства новых станций [9], что открывает дополнительные возможности в исследовании материалов в экстремальных условиях $[10,11]$. Это также позволит плавно перейти в процессе модернизации от текущих параметров пучка на существующих станциях к улучшенным характеристикам, избегая серьезных изменений оптической схемы [12].

Применения преломляющей оптики могут быть распространены в область Фурье-оптики, когерентной дифракции и микроскопии [12-16]. Для изучения 3-D структуры фотонных кристаллов и мезоскопических материалов [17-19] были предложены методы когерентной дифракционной микроскопии и высокоразрешающие дифракционные методы, использующие преломляющую линзу в качестве Фурье-преобразователя. Особый интерес представляют формирователи пучка аксиконы [20], позволяющие создавать волновые 
фронты заданной формы. В этой связи использование новых аддитивных технологий 3-х мерной печати для моделирования и создания рентгеновской микрооптики трудно переоценить [21,22].

Рентгеновская интерферометрия - еще одно перспективное направление развития преломляющей оптики. Недавно предложенные многолинзовые интерферометры могут генерировать интерференционное поле с переменным периодом в диапазоне от десятков нанометров до десятков микрометров [23-25]. Этот простой способ создания рентгеновской стоячей волны в параксиальной геометрии открывает возможность разработки новых методов рентгеновской интерферометрии для изучения природных и искусственных наноматериалов, таких как самоорганизующиеся биосистемы, фотонные и коллоидные кристаллы, объекты наноэлектроники. Такое устройство может быть использовано в качестве классического интерферометра для построения фазово-контрастных изображений и радиографии, а также может быть полезно для характеризации когерентных свойств высокоэнергетичных рентгеновских источников.

О том, что прогресс последних лет в технологии роста многослойных интерференционных зеркал
(МИЗ) нормального падения позволил приступить к решению амбициозной задачи - переносу традиционных методов управления световыми пучками в экстремальный ультрафиолетовый (ЭУФ) и мягкий рентгеновский (MP) диапазоны длин волн, участники семинара узнали из выступления сотрудников Института физики микроструктур РАН, Нижний Новгород, (Н.И. Чхало, А.Е.Пестов, В.Н. Полковников, Н.Н. Салащенко, М.Н. Торопов) «Рентгеновская оптика дифракционного качества: технология, метрология, применения".

Благодаря короткой длине волны, низкому рассеянию и резонансному характеру взаимодействия с веществом излучение этого диапазона предоставляет уникальные возможности для нанофизики, нанотехнологии и нанодиагностики веществ. Наибольший объем информации о физических процессах, происходящих на Солнце, получен из исследований короны Солнца в ЭУФ- и МР- диапазонах. Широкополосные МИЗ позволяют транспортировать, фокусировать, проводить спектральный анализ атто- и суб-атто- секундных импульсов электромагнитного излучения без "размытия" волнового пакета, либо даже укорачивать его во времени.

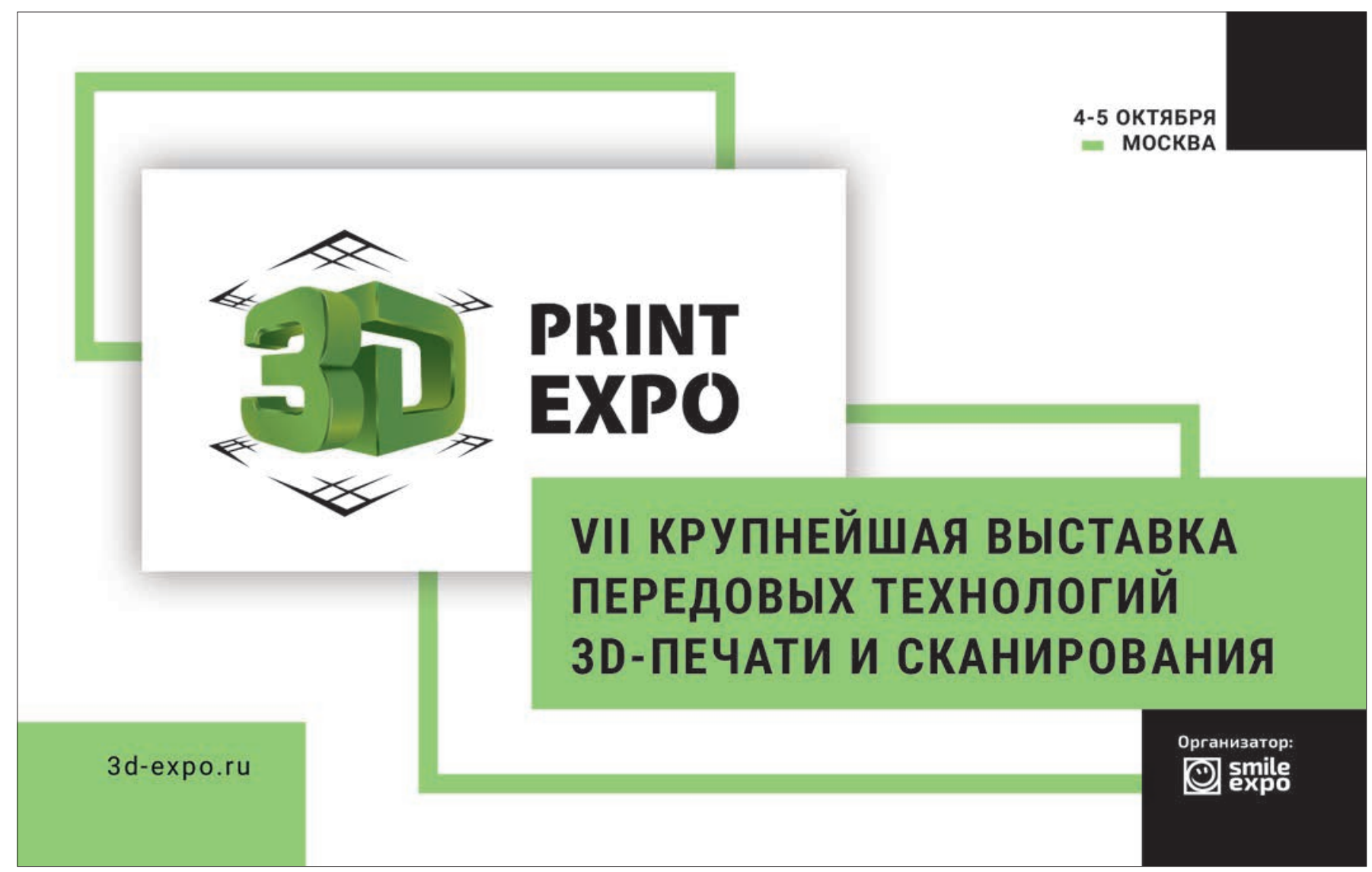

Photonics VOL. 13 № 52019501 
Для использования потенциала МИЗ для изображения и транспортировки пучков без искажений волновых фронтов необходима оптика дифракционного качества для рентгеновского диапазона. По сравнению с традиционной оптикой ее точность должна быть как минимум на два порядка выше. Традиционные методы изготовления и изучения зеркал не обеспечивают этих требований. В докладе сообщалось о развиваемых в ИФМ РАН новых методах изготовления и характеризации оптики дифракционного качества для ЭУФ- и МР-диапазонов. Были представлены примеры применения обсуждаемых рентгеновских оптических элементов оптики для задач внеземной астрономии, рентгеновской микроскопии и литографии.

Доклад "Многослойная рентгеновская оптика на основе бериллия" (В.Н.Полковников, Н.Н. Салащенко, Н.И. Чхало, Институт физики микроструктур РАН, Нижний Новгород) был посвящен исследованиям бериллий-содержащих многослойных зеркал (М3). Еще в 1990-х годах бериллий применялся в мягком рентгеновском (MP) и экстремальном ультрафиолетовом (ЭУФ) диапазонах в качестве слабопоглощающего материала (спейсера). Однако М3 на основе спейсера Ве обеспечивали высокие коэффициенты отражения только в очень узком диапазоне длин волн 11,2-12,4 нм. На других длинах волн бериллий-содержащие М3 уступали традиционным M3 на основе спейсеров Si, Al и Mg. В ходе наших работ было показано, что в диапазоне длин волн $\lambda>17,1$ нм бериллий обладает уникальным сочетанием мнимой и действительной частей показателя преломления. Это позволяет использовать Ве в качестве рассеивающего материала и в этом качестве одновременно получать и рекордно высокие коэффициенты отражения и спектральную селективность. Гладкость дисперсионной зависимости коэффициента преломления Ве позволяет использовать его в коротковолновой части МР-спектра в качестве основы М3, предназначенных для применения в широком диапазоне длин волн. Кроме того, применение методики барьерных слоев позволило нам добиться рекордных значений отражения бериллий-содержащих M3 в диапазоне 11,2-14 нм.

Методы повышения разрешения и чувствительности в микротомографии путем использования рентгено-оптических элементов были рассмотрены в докладе В.Е.Асадчикова, Институт кристаллографии им.А.В.Шубникова ФНИЦ «Кристаллография и фотоника" РАН. В настоящее время рентгеновская томография является широко распространенным методом исследования пространственной структуры объектов в различных областях науки и техники. Компьютерная (рентгеновская) томография стала одним из основных диагностических методов в современной медицине. Однако достигаемые в этих приборах пространственное разрешение и чувствительность оказываются недостаточными для использования приборов во многих иных применениях. Существенным недостатком серийных рентгеновских томографов является тот факт, что инструменты обеспечивают возможность определения поглощения лишь в относительной шкале Хаунсфельда.

Повышение разрешения и чувствительности в настоящее время (ввиду ряда ограничений) может быть достигнуто лишь при уменьшении поля зрения. По этой причине активно ведутся исследования в области рентгеновской микротомогрфии. Основными возможностями повышения разрешения являются проекционное увеличение при использовании микрофокусных источников и/или использование рентгено-оптических элементов. К их числу относятся капилярные линзы, зонные пластинки Френеля, асимметричные отражающие кристаллы (Bragg magnifiers), а также многослойные рентгеновские зеркала, которые, однако, могут быть эффективно применены лишь для мягкого рентгеновского излучения. Отметим, что применение монохроматичного излучения позволяет определять значения линейных коэффициентов поглощения, что существенно повышает качество получаемой информации.

В докладе были показаны возможности применения этих элементов в рентгеновской микротомографии как в нашей стране, так и за рубежом. Отдельное внимание докладчик уделил вопросу повышения чувствительности рентгеновских томографов путем применения фазочувствительных методов. Это также достигается использованием различных рентгено-оптических элементов. К последним, кроме перечисленных, относятся и дифракционные решетки (Тальбоинтерферометрия). Были приведены примеры исследования трехмерной структуры образцов разной природы при варьировании пространственного разрешения.

Рентгеновская оптика косого падения и ее приложение в проекте орбитальной астрофизической обсерватории "Спектр-РГ» были рассмотрены в докладе с одноименным названием группы авторов из ИКИ РАН и РФЯЦ-ВНИИЭФ, Саров (М. Н. Павлинский, А.А. Лутовинов, А.Ю.Ткаченко (ИКИ РАН, Москва); С. В.Григорович (РФЯЦ-ВНИИЭФ, 
Саров). В период с 2007 по 2016 год в ИКИ РАН и РФЯЦ-ВНИИЭФ велась работа по изготовлению рентгеновского зеркального телескопа косого падения ART-XC для орбитальной астрофизической обсерватории "Спектр-РГ» (запуск обсерватории запланирован на 21 июня 2019 года). В рамках этих работ шла разработка технологий изготовления рентгеновских зеркал методом гальванопластики на основе никеля и никель-кобальта с иридиевым покрытием. Сложность задачи заключалась в изготовлении зеркал, позволяющих работать до энергий $\sim 30$ кэВ с угловым разрешением $\leq 1^{\prime}$ в поле зрения более $\geq 30$ '. Участнкам обсуждения были представлены технологические наработки, решение задачи метрологического обеспечения и результаты наземных испытаний на специализированном калибровочном стенде рентгеновской оптики косого падения в паре с разработанным позиционно-чувствительным и спектрометрическим полупроводниковым детектором на базе CdTe. В совокупности семь зеркальных систем телескопа ART-XC обеспечивают эффективную площадь $\sim 60 \mathrm{~cm}^{2}$ по оси зрения на энергии 8 кэВ.

\section{СПИСОК ЛИТЕРАТУРЫ}

1. A. Snigirev, V. Kohn, I. Snigireva, B. Lengeler. Nature. 1996; 384: 49.

2. G. B. M. Vaughan, J.P. Wright, A. Bytchkov et al. J. Synchrotron Rad. 2011; 18: 125.

3. M. Polikarpov, I. Snigireva, A. Snigirev. J. Synchrotron Rad. 2014; 21: 484.

4. M. Lyubomirskiy, I. Snigireva, A. Snigirev. Optics express. 2016; 24: 13679.

5. M. Polikarpov, I. Snigireva, J. Morse et al. J. Synchrotron Rad. 2015; 22: 23.

6. S. Terentyev, V. Blank, S. Polyakov et al. Appl. Phys. Let. 2015; 107: 111108.

7. M. Polikarpov, I. Snigireva, A. Snigirev. AIP Conference Proceedings. 2016; 1741: 040024.

8. Q. Zhang et al. J. Synchrotron Rad. 2019; 26:109

9. M.W. Bowler, D. Nurizzo, R. Barrett et al.J. Synchrotron Rad. 2015; 22: 1540.

10. N. Dubrovinskaia, L. Dubrovinsky, N. A. Solopova et al. Sci. Adv. 2016; 2: e1600341.

11. F. Wilhelm, G. Garbarino, J. Jacobs et al. High Pressure Research. 2016; 36: 445.

12. Orange Book "ESRF Upgrade programme Phase II 92015-2022). Technical Design Study", C. Admans et al eds. 2014.

13. V. Kohn, I. Snigireva, A. Snigirev. Opt. Comm. 2003; 216: 247.

14. M. Drakopoulos, A. Snigirev, I.Snigirev, J. Schilling. Appl. Phys. Lett. 2005; 86: 014102

15. P. Ershov, S. Kuznetsov, I. Snigireva et al. Appl. Cryst. 2013; 46: 1475.

16. H. Simons, A. King, W. Ludwig et al. Nature Communications. 2015; 6: 6098

17. A. Bosak, I. Snigireva, K. Napolskii, A. Snigirev. Adv. Mater. 2010; 22: 3256.

18. D.V. Byelov, J.-M. Meijer, I. Snigireva et al. RSC Advances. 2013; 3: 15670.V.

19. V. Kohn, I. Snigireva, A. Snigirev. J. Synchrotron Rad. 2014; 21: 729.

20. D. Zverev, A. Barannikov, I. Snigireva, A. Snigirev. Opt. Express. 2017; 25: 28469-28477.

21. A. K. Petrov, V. O. Bessonov, K. A. Abrashitova et al. Opt. Express. 2017; 25: 14173.

22. A. Barannikov, M. Polikarpov, P. Ershov et al. J. Synchrotron Rad. 2019.

23. A. Snigirev, I. Snigireva, V. Kohn et al. Phys. Rev. Lett. 2009; 103: 064801.

24. A. Snigirev, I. Snigireva, M. Lyubomirskiy et al. Optics express. 2014; 22(21): 25842.

25. M. Lyubomirskiy, I. Snigireva, V. Kohn et al. J. Synchrotron Rad. 2016; 23: 1104.

при финансовой поддержке Новороссийских предприятий - ООО "НПФ АВТЭК" и ЗАО "НЦЗ "Горный

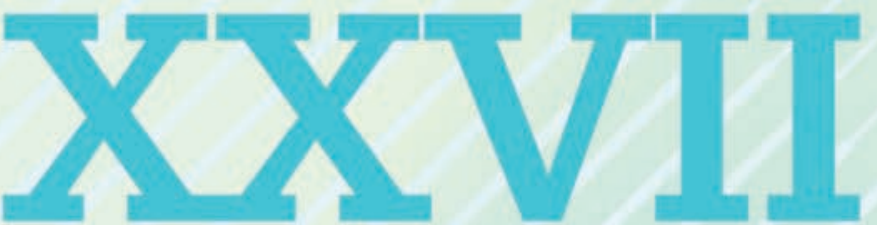

Международная Конференция

\section{9-14 сентября 2019 года}

НА КОНФЕРЕНЦИИ БУДЕТ РАБОТАТЬ ВЫСТАВКА ОПТИЧЕСКИХ ПРИБОРОВ, ВКЛЮЧАЯ ЛАЗЕРЫ, А ТАКЖЕ СОПУТСТВУЮЩИЕ ИЗДЕЛИЯ ЭЛЕКТРОНИКИ И МЕХАНИКИ.

БУДУТ ПРЕДСТАВЛЕНЫ СТЕНДЫ С ИНФОРМАЦИЕЙ О ДЕЯТЕЛЬНОСТИ РАЗЛИЧНЫХ ЛАЗЕРНЫХ ЛАБОРАТОРИЙ И ОРГАНИЗОВАНА ВЫСТАВКА СПЕЦИАЛИЗИРОВАННОЙ ЛИТЕРАТУРЫ.
ЛАЗЕРНО-ИНФОРМАЦИОННЫЕ ТЕХНОЛОГИИ В МЕДИЦИНЕ, БИОЛОГИИ, ГЕОЭКОЛОГИИ И НА ТРАНСПОРТЕ-2019

\section{ТЕМАТИКА КОНФЕРЕНЦИИ}

-Лазеры в медицине и биологии

-Лазеры на парах металлов

-Лазеры в геоэкологии

-Лазерные технологии на транспорте

- Системы обработки и анализа

изображений и сигналов

-Компьютерные технологии

- Нанотехнологии

-Геотехнологии

- Техносферная безопасность

•Геоэкологический мониторинг 


\title{
Земля в объятиях Солнца: гелиофизика и космическая погода
}

\begin{abstract}
Очередное заседание Научной сессии Отделения физических наук (научный руководитель - академик РАН Р. А. Сурис) прошло 5 июня 2019 года. Тематика объединила доклады о самых новых результатах в исследованиях Солнца и его влиянии на космическую погоду.
\end{abstract}

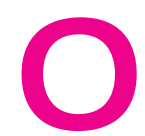

новых результатах наблюдения Солнца со сверхвысоким пространственным разрешением рассказал д.т.н. С.А.Бога чев (ФИАН, Москва). Длительные исследования Солнца привели к общепринятому выводу, что энергии наблюдаемой солнечной активности недостаточно для объяснения фундаментальных свойств солнечной короны - прежде всего, ее высокой температуры. В 1988 году американский астроном Юджин Паркер высказал предположение о существовании на Солнце так называемых нановспышек - событий, мощность которых на 6-9 порядков уступает мощности большой вспышки, но интегральное энерговыделение которых может на порядки превосходить крупномасштабную компоненту активности. За последние 10-15 лет солнечные нановспышки, а также промежуточный класс - микровспышки - стали наблюдаемым явлением.

Одновременно появились свидетельства существования на Солнце гораздо более широкого

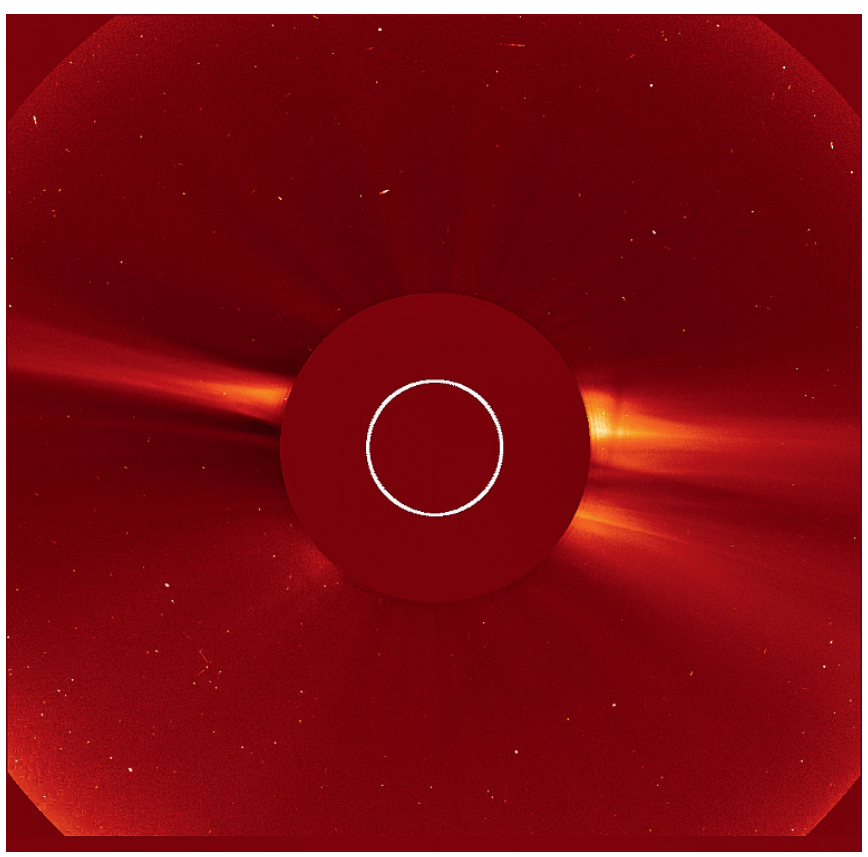

набора мелкомасштабных явлений - яркие рентгеновские точки, спикулы разных типов, бомбы Элермана. В докладе приводятся результаты отечественных космических экспериментов, проведенных Российской академией наук и Российским космическим агентством, а также последние данные с зарубежных космических обсерваторий. В рамках Федеральной космической программы РФ на 2016-2025 годы предусматривается создание специализированной солнечной обсерватории "АРКА", которая должна впервые предоставить изображения короны Солнца с угловым разрешением 0,1 угловых секунд (менее 100 км). Есть надежда, что полученная информация позволит добиться решающего прогресса в понимании баланса между крупномасштабной и мелкомасштабной энергетикой на Солнце, а может быть и ответить, наконец-то, на фундаментальный вопрос - что же греет корону Солнца.

Доклад "Современный взгляд на солнечный ветер, от микро- до макро-масштабов" (А. А. Петру-

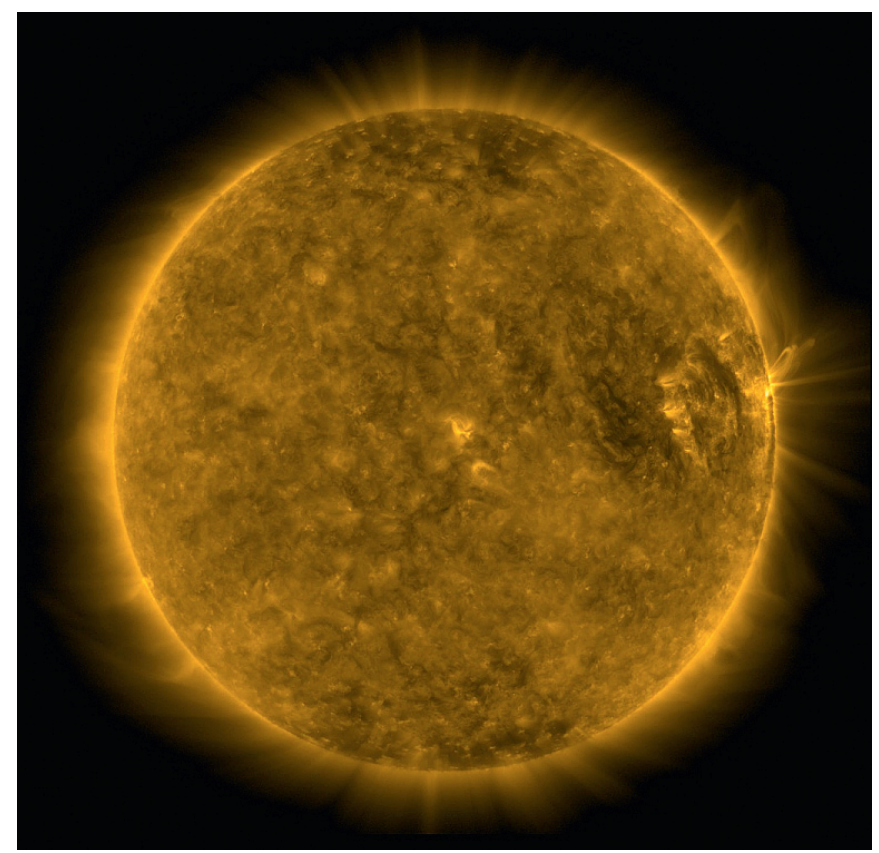




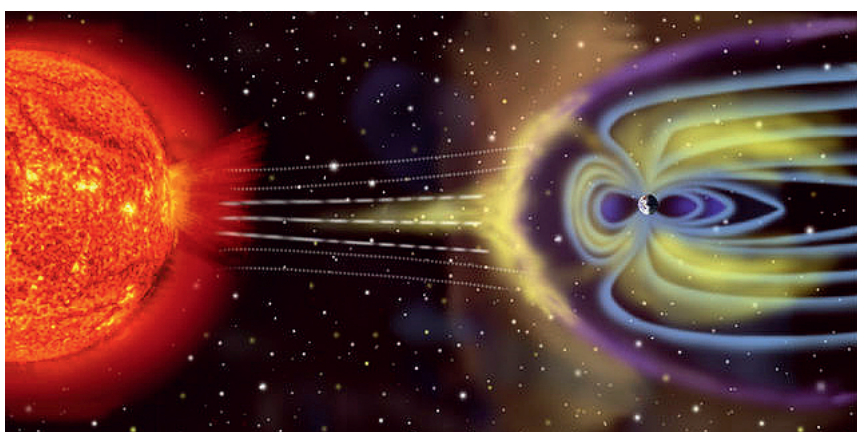

кович, М.О. Рязанцева, Х.В. Малова, ИКИ РАН, Москва) был посвящен одному из важнейших элементов солнечной системы - солнечному ветру. Плазма солнечного ветра - уникальная лаборатория специфической астрофизической среды с доминированием потоковой энергии. Обзор современных результатов по исследованию происхождения и динамики солнечного ветра охватил структуру сразу нескольких научных направлений, подчеркнув логику исследований. На микромасштабах определена спектральная структура турбулентности потока, выявлены новые виды изолированных нелинейных структур с характерными размерами порядка ионного кинетического масштаба. Столкновения потоков солнечного ветра между собой и с планетами формируют ударные волны. Многоточечные спутниковые наблюдения позволяют определить моду плазменных колебаний, ответственных за создание бесстолкновительного фронта волны. На средних масштабах (до миллиона километров) доминируют структуры, имеющие происхождение на Солнце и модифицированные в ходе распространения. Эти структуры играют важную роль в генерации магнитной активности на Земле. Анализ динамики таких структур показывает интересную возможность улучшения прогноза их развития при увеличении их размера, что имеет практическую важность для прогноза магнитных бурь по мониторингу солнечного ветра. На макромасштабах порядка гелиосферы структура солнечного ветра определятся конфигурацией основного магнитного поля Солнца и может быть прослежена на межпланетных космических аппаратах.

В.Д. Кузнецов (ИЗМИРАН, Троицк) выступил с обзором «Гелиофизика: от наблюдений к моделям и приложениям". На основе наблюдений и построения физических моделей он рассмотрел проблемные вопросы физики Солнца - глобальные колебания в недрах Солнца, триггерные механизмы наиболее мощных проявлений солнечной активности - вспышек и выбросов массы, нагрев солнеч- ной короны, ударные волны в бесстолкновительной плазме солнечного ветра. Изучаемые явления солнечной активности рассмотрены как источники космической погоды в околоземном космическом пространстве были рассмотрены в приложении к практическим вопросам воздействия ее факторов на сферы человеческой деятельности на Земле и в космосе. В докладе была рассмотрена структура научных задач, направленных на решение таких актуальных проблем физики Солнца как изменчивость длительности и высоты солнечных циклов, триггерные механизмы солнечных вспышек и выбросов массы, механизмы ускорения частиц в солнечной атмосфере и гелиосфере, нагрев солнечной короны и ускорение солнечного ветра, и некоторые другие. Эти задачи решаются в рамках космического проекта "Интергелиозонд" Федеральной космической программы РФ.

О существующих радиационных полях в космосе и необходимостью в связи с их величинами планирования космических миссий рассказал М.И. Панасюк (НИИЯФ МГУ, Москва). Для бортовой электроники и долговременных пилотируемых полетов все большую актуальность приобретает проблемы, связанные с присутствием в составе космической радиации тяжелой компоненты заряженных частиц и полей вторичных нейтронов. Присутствие радиации в космическом пространстве обусловлено существованием радиационных полей. К ним относятся: радиационные пояса Земли (РПЗ) и некоторых других планет солнечной системы, галактические космические лучи (ГКЛ) и солнечные космические лучи (СКЛ). Эти радиационные компоненты состоят из различных частиц, среди которых протоны, электроны и тяжелые ядра (ионы) химических элементов:

- ГКЛ, потоки которых проникают в Солнечную систему из нашей и других галактик;

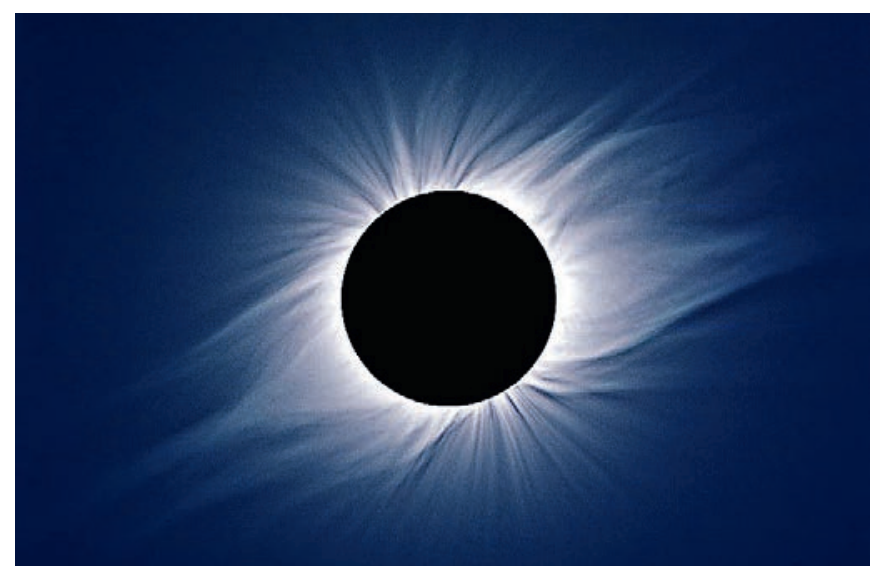


- СКЛ, которые эпизодически появляются в Солнечной системе как следствие генерации хромосферных вспышек и корональных инжекций масс на Солнце;

- РПЗ, захваченные в магнитной ловушке магнитосферы Земли, которая удерживает частицы солнечного и атмосферного (ионосферного) происхождения, а также продукты ядерных реакций, возникающие из-за взаимодействия космических лучей с атмосферой Земли.

Установлено, что энергетический диапазон и уровень потоков частиц в радиационных полях, а, следовательно, и уровень радиационной опасности варьируются в значительных пределах, что связано как с пространственно- неоднородным распределением этих потоков в межпланетном и околоземном космическом пространстве, так и с изменениями этих потоков во времени из-за временной изменчивости физических процессов, протекающих в Галактике и Солнечной системе. В этом плане развитие систем мониторинга космической радиации с возможностью оценки радиационных условий в реальном времени приобретает исключительно важное значение. Для практических приложений установленные физические параметры потоков частиц ГКЛ, РПЗ и СКЛ и закономерности их вариаций обобщаются с помощью физико-математических моделей и также являются неотъемлемым компонентом расчетов при оценках радиационной опасности. В докладе был дан обзор современного состояния проблем экспериментального исследования, мониторинга и моделирования радиационных полей в космосе, актуальных для осуществления долговременных околоземных и будущих космических миссий освоения Луны, Марса.

Доклад "Рентгеновское и гамма-излучение солнечных вспышек" (Д.Д.Фредерикс, А. Л. Лысенко, Д. С. Свинкин, М. В. Уланов, А. Е. Цветкова, Р.Л.Аптекарь, ФТИ им. А.Ф.Иоффе, Санкт Петербург) был посвящен краткому обзору последних результатов по наблюдениям солнечных вспышек в диапазонах жесткого рентгеновского и гамма-излучения. Они особенно важны для диагностики ускоренных частиц, поскольку именно в них наблюдается тормозное излучение нетепловых электронов и гамма-линии от ядерных реакций ускоренных ионов. Процессы ускорения частиц и нагрева плазмы типичны для многих астрофизических объектов, при этом Солнце, ближайшая к нам звезда, является уникальной естественной лабораторией, где они могут быть изучены с уни-

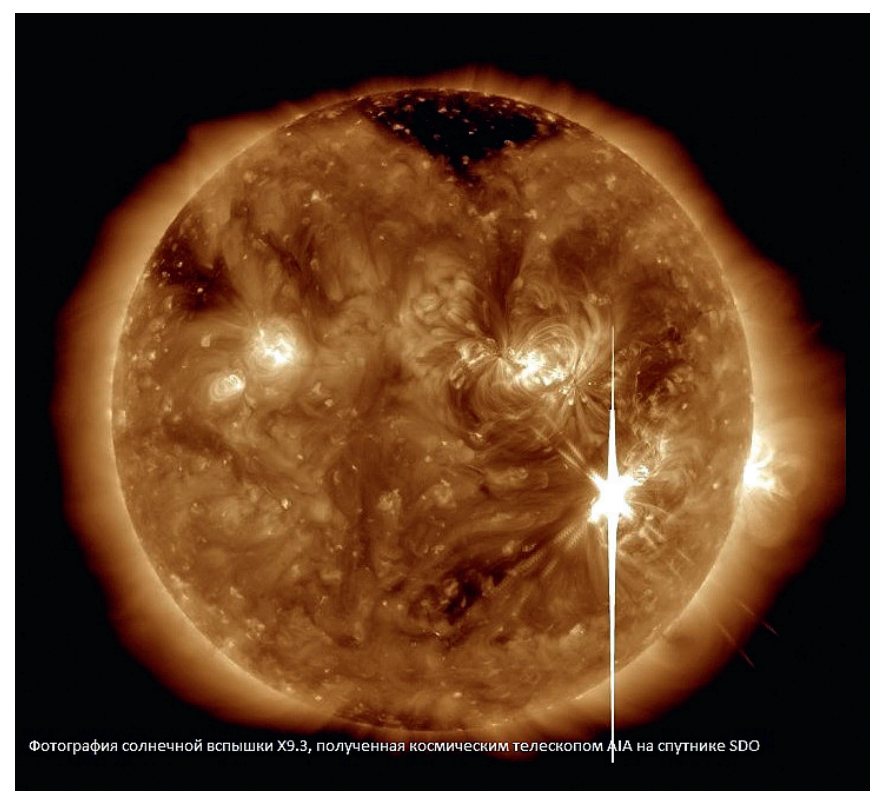

кальным пространственным и временным разрешением. Хотя в последнее десятилетие и был достигнут значительный прогресс в понимании морфологии солнечных вспышек, однако, в их физике остается много нерешенных вопросов, к числу которых относятся, например, выяснение конкретных механизмов ускорения частиц и проблема нагрева солнечной короны, температура которой на порядки градусов превышает температуру фотосферы.

Были представлены результаты, полученные ФТИ им. А.Ф. Иоффе РАН в ходе совместного российско-американского космического эксперимента "Конус-Винд", который проводит непрерывный мониторинг вспышечной солнечной активности в диапазоне 20 кэВ - 15 МэВ, начиная с ноября 1994 года. Аппаратура эксперимента "Конус» - два сцинтилляционных гамма-спектрометра. Они установлены на спутнике "Винд", стабилизированном вращением таким образом, что они постоянно осматривают всю небесную сферу. Орбита спутника расположена полностью в межпланетном пространстве (в так называемой точке либрации L1, примерно в 1,5 миллиона километров от Земли на линии "Земля - Солнце»), то есть вне радиационных поясов Земли, которые представляют опасность для детекторов. Также благодаря этому Земля не закрывает детекторам обзор каких-либо участков небесной сферы. Важная задача эксперимента - определение координат источников гамма-всплесков триангуляционным методом по данным межпланетной сети спутников (InterPlanetary Network, IPN) с детекторами гамма-квантов на борту.

gpad.ac.ru 


\section{УСПЕШНЫЙ ЗАПУСК АСТРОФИЗИЧЕСКОЙ ОБСЕРВАТОРИИ "СПЕКТР-РГ»}

С космодрома Байконур 13 июля 2019 года состоялся успешный пуск ракеты-носителя Протон-М" с разгонным блоком "ДМ-03" и космической астрофизической обсерваторией "Спектр-РГ». Космический аппарат "Спектр-РГ» создан в рамках Федеральной космической программы России по заказу Российской академии наук с участием Германии. Обсерватория оснащена двумя уникальными рентгеновскими зеркальными телескопами: ART-ХC (производства ИКИ РАН, Россия) и еROSITA (MPE, Германия), работающими по принципу рентгеновской оптики косого падения. Телескопы установлены на космической платформе «Навигатор" (НПО Лавочкина, Россия), адаптированной под задачи проекта. Научный руководитель миссии - академик Рашид Алиевич Сюняев; научный руководитель по телескопу ART-ХC (Россия) - д.ф.-м.н. Михаил Павлинский; научный руководитель по телескопу eROSITA (Германия) - Dr. Петер Предель.

"Спектр-РГ" будет работать в точке Лагранжа L2, которая находится примерно в 1,5 миллиона километров от Земли. Прибытие и выход на рабочую орбиту вокруг L2 запланированы на 21 октября 2019 года.

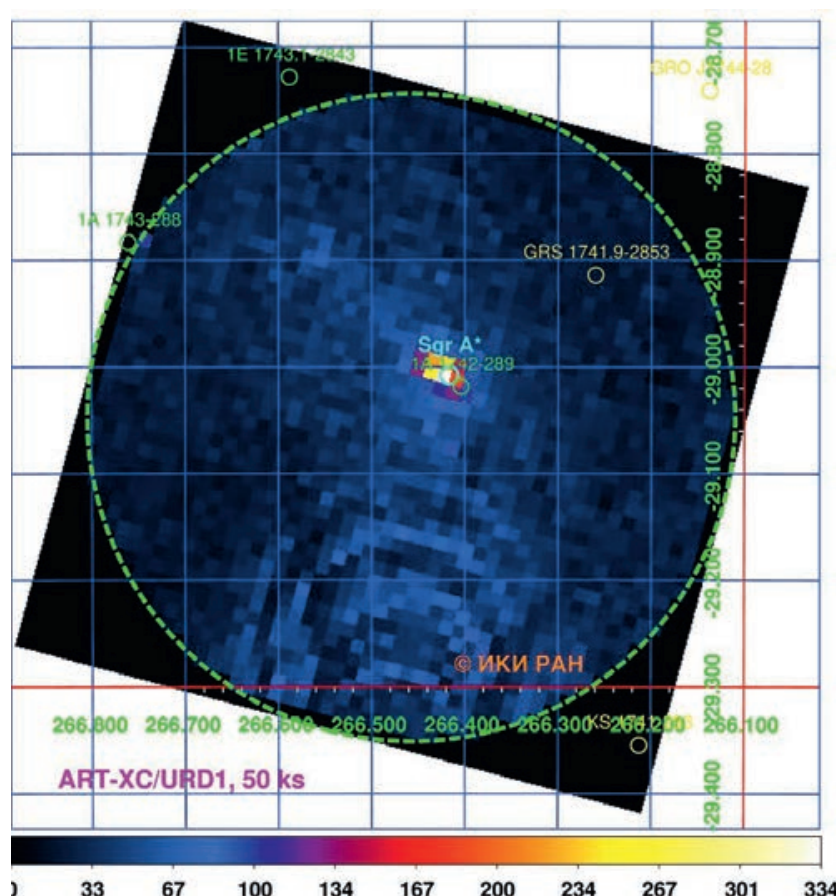

Второй телескоп проекта eROSITA передал первое рентгеновское изображение 27 августа 2019 года.

\section{ПРИГЛАШАЕМ ВАС ПРИНЯТЬ УЧАСТИЕ В РАБОТЕ ШКОЛЫ, КОТОРАЯ СОСТОИТСЯ}

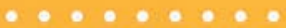

$\because \cdots \cdots$

$\cdots \cdots \cdots \cdots$

30 сентября - 4 октября 2019 года

в г. Екатеринбурге

$\cdots \cdots \cdots$

Тематика Школы включает в себя следующие направления:

теоретические методы оптической голографии

и анализа свойств голограмм:

цифровая обработка изображенийр

• новые методы голографической и спекл-интерферометрии; спекл-корреляционные методы:

изобразительная голография

(физические и цифровые методы):

голографические технологии в биологии и медицине;

применение когерентно - оптических методов в диагностике деформаций, повреждений и остаточного ресурса: голограммные и дифракционные оптические злементы;

фотоматериалы, среды для регистрации голограмм;

технология защитных голограмм

голография и образование:

- пюминесцентные материалы и технологии

- фотоника перспективных материалов:

- спектроскопия квантовых точек и одиночных молекул;

• оптические свойства метаматериалов. $\bullet \bullet \bullet \bullet \bullet \bullet$

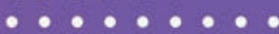

организаторы: Уральский Федеральный Университет имени первого Президента России Б. Н. Ельцина

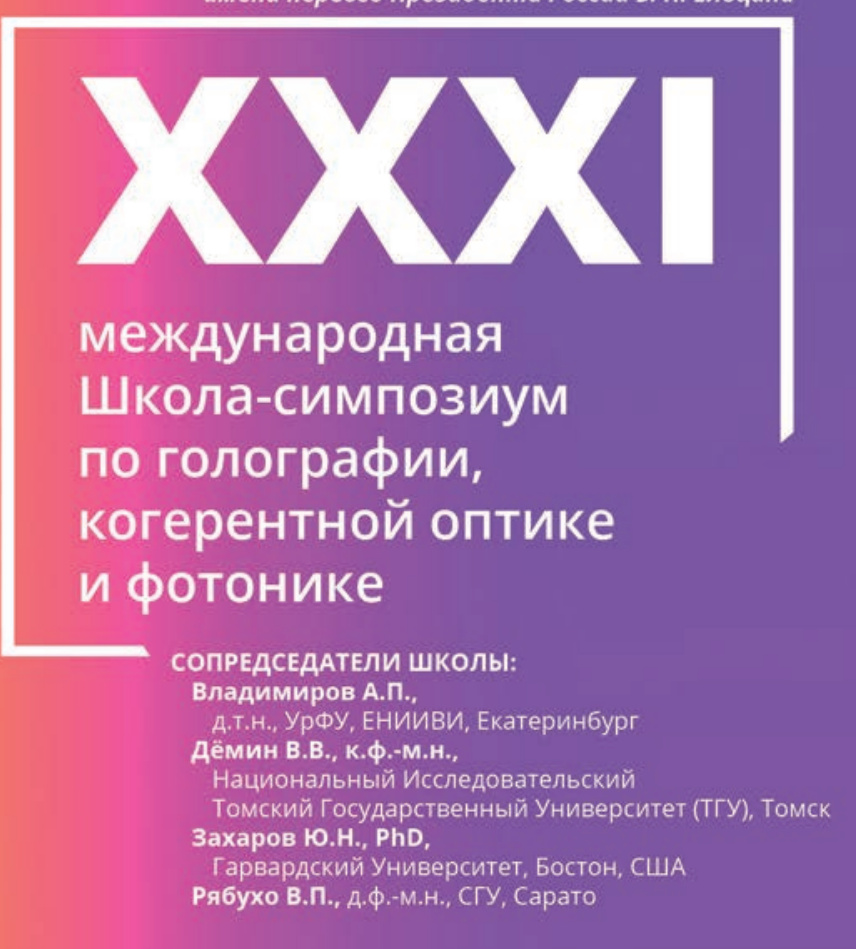


TEXHOCФEPA РЕКЛАМНО-ИЗДАТЕЛЬСКИЙ ЦЕНТР

\section{0\% ГАРАНТИЯ} ПОЛУЧЕНИЯ ВСЕХ НОМЕРОВ

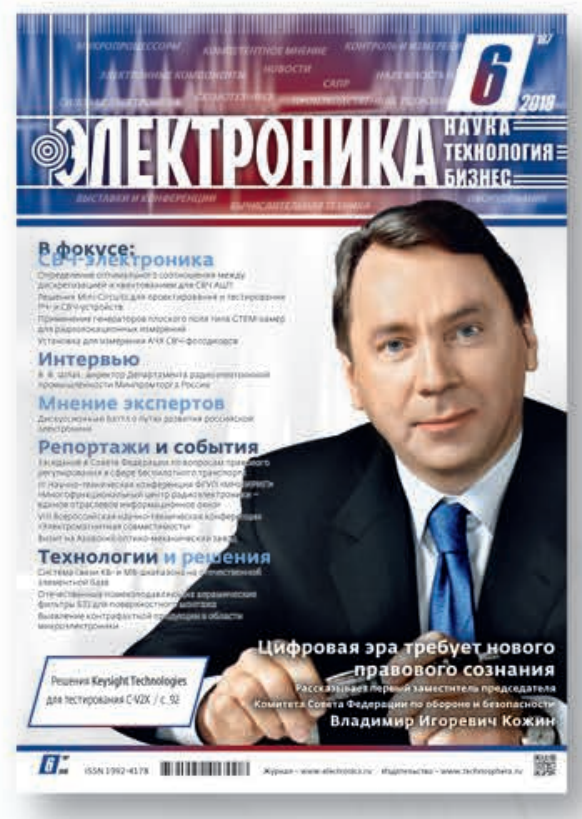

Стоимость 2200 р. за номер

Периодичность: 10 номеров в год www.electronics.ru

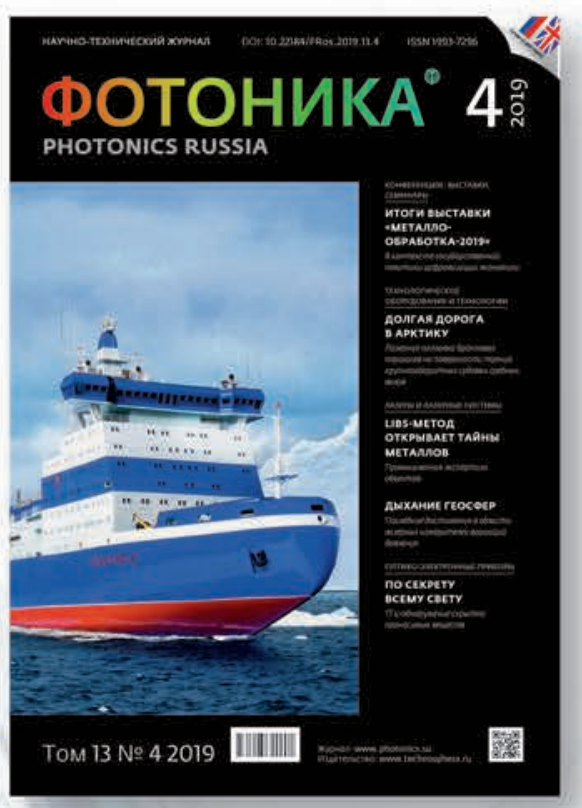

Стоимость 1430 р. за номер

Периодичность: 8 номеров в год www.photonics.su

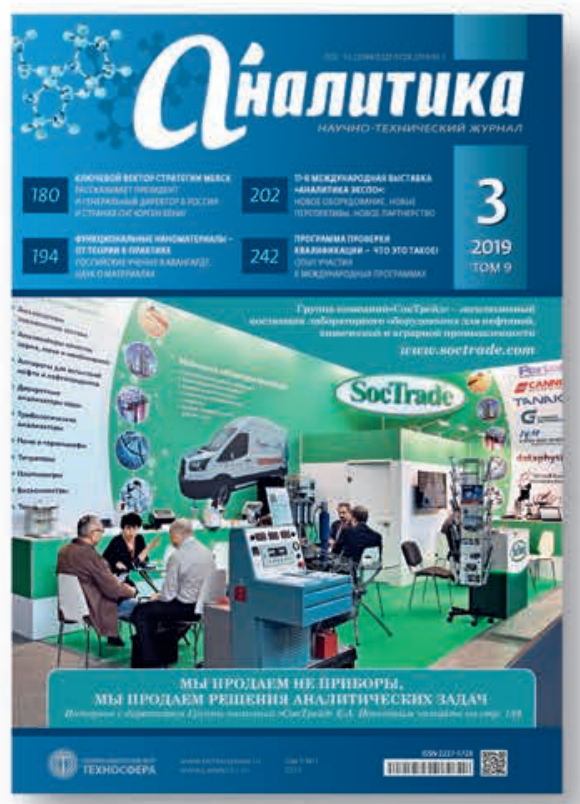

Стоимость 1430 p. за номер

Периодичность: 6 номеров в год www.j-analytics.ru

\section{ПОДПИСКА НА ХУРНАЛЬ}

\section{www.technosphera.ru}

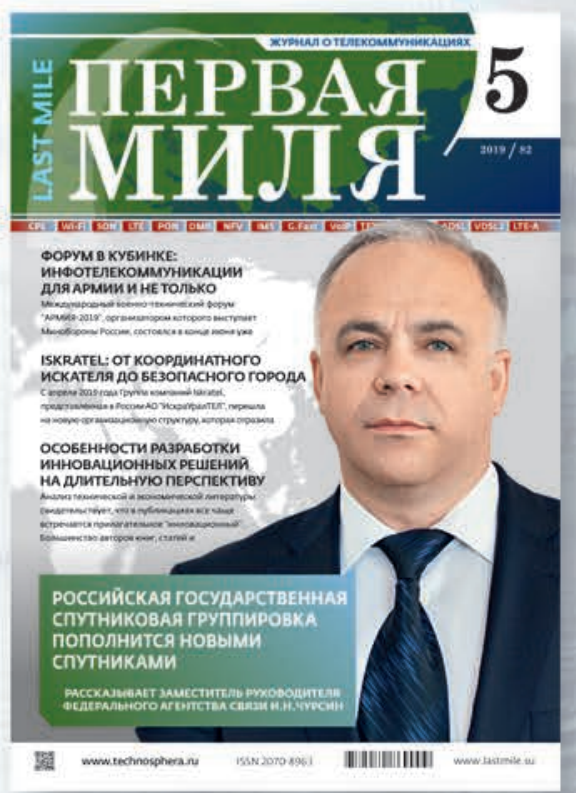

Стоимость 1056 р. за номер

Периодичность: 8 номеров в год www.lastmile.su

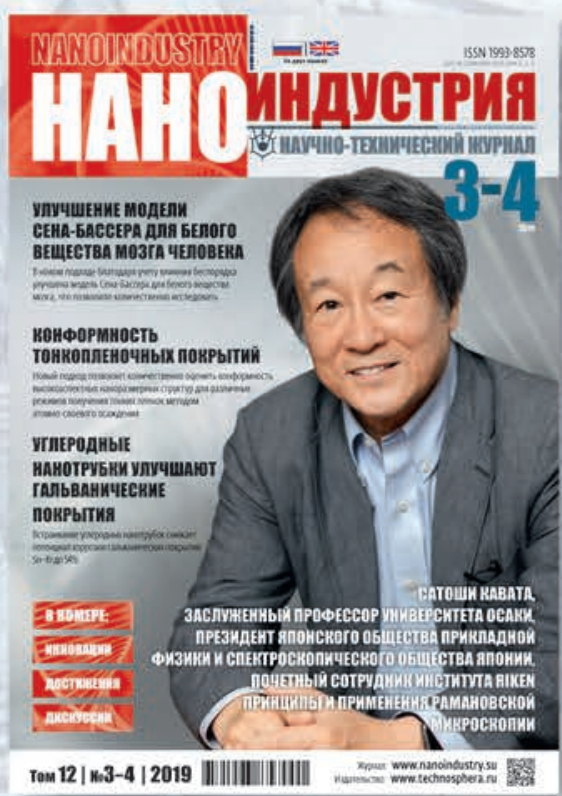

Стоимость 1287 р. за номер

Периодичность: 8 номеров в год www.nanoindustry.su

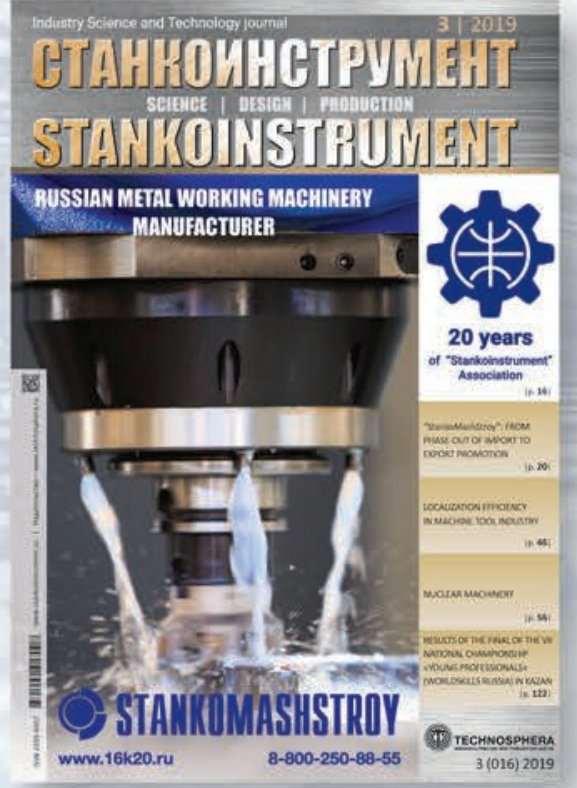

Стоимость 1716 р. за номер

Периодичность: 4 номера в год www.stankoinstrument.su 